\title{
Game boards as a review tool: an experience with undergraduate engineering students
}

\author{
C. Ibáñez, R. Palma, D. Hernández-Figueirido \\ Department of Mechanical Engineering and Construction \\ Universitat Jaume I, Castelló de la Plana (Spain)
}

\begin{abstract}
The use of games with educational purposes has a lot of benefits since it creates attractive scenarios for learning combining different techniques like rewards, competitions or challenges. Computer games as a teaching instrument have been very popular among educators in the last years. However, some difficulties may arise to find the appropriate game given the specific aims of each subject which is more remarkable in higher education. Besides, the current reduced education budgets have led lecturers to search for alternatives. Game boards can be a good option since they have a low cost and can be easily customized. In the present work, an experiment carried out with undergraduate students of mechanical engineering at the Universitat Jaume I (Castelló de la Plana, Spain) is described. A questions game board created by the students was used as a review tool. During the course, the students proposed questions to be incorporated to the game working in groups. In the last session it was used in an organized competition among the students. Working in groups enhances communication and collaboration whereas using the elaborated game as a review tool help to summarize and reinforce essential concepts. In general, students were very interested and motivated to acquire new knowledge.
\end{abstract}

Keywords: board games; questions games; traditional games; engineering students; creating games

\section{Introduction}

The use of games with educational purposes has several advantages. Including games as a method for teaching encourage simultaneously collaboration and discussion and sharpen up students thinking. Besides, games can be used as review tools to summarize and reinforce essential concepts and information since they offer an attractive environment for information assimilation. According to Salies (2002) the interactive structure generated during a game improves the transfer of learning and presents social benefits for the student.

Traditionally the use of games has been more present in primary and high school classes maybe due to the ratio of students per class, but in the last years their use has been extended to the university frame. Games are very versatile and, as Sharp (2012) pointed out, they can fit in almost every subject creating original learning opportunities which accommodate the different learning styles of the students

Several authors, such as Hays (2005), Fisch (2005) and Katmada (2014), who carried out game-based experiences obtained encouraging findings: the students had very good disposition to realize the activity and appreciate learning activities based in games.

In addition, as Carlson remarked (2005), the new generation of undergraduate students is specially focused on new technologies. They get distracted easily, are impatient and exceptionally capable of multitasking. Therefore, keeping their attention and motivation during a whole class is a hard task which leaves educators in the position of looking for new learning techniques and innovative activities to encourage learning among their students as Sharp (2012) noted. Marzano (2007) identified this situation as an appropriate opportunity for educators to take advantage to generate enthusiasm, encourage competition and increase student engagement by 
means of the development of game-based activities which, at the same time, refocus their attention on the curriculum.

With regard to computer games and accordingly to Whitton (2012), there is no discussion about their benefits as a tool for teaching but it can be an expensive option when new software needs to be purchased or when it is necessary to develop new interfaces or graphics.

Due to the global financial crisis, education budgets are readjusted every academic year and educators suffer the pressure of reducing costs from their daily teaching practice. Besides the economic issue, another inconvenient that may arise during the election of a commercial game is finding the one which fits the specific content to be covered. Commercial games are in general designed with the aim of entertaining and rarely they match the educators expectations. In those cases, a good option for educators can be designing and developing their own games but, sometimes, the lack of programming skills and the development time required make it not possible to create computer games of an acceptable quality as explained Whitton (2012).

However, some authors like Baker et al. (2003) and Moseley (2011) suggested that, for those lecturers eager to implement their innovative ideas, a great alternative could be going back to traditional games. Board games is an excellent option since it only involves the ability of producing the components related to the game being developed but technical skills are not needed.

In particular, board games are suitable for multitude of different situations and allow students to recover the proximity and the face-to-face component of traditional games which provide so many benefits in terms of cooperative development and social skills.

This paper describes the experience of developing a questions game board and using it as a review tool. The game was developed by third grade undergraduate students along the duration of the course. The experiment was carried out in the subject of Industrial Constructions and Structures within the frame of the Mechanical Engineering degree at the Universitat Jaume I (Castelló de la Plana, Spain).

The aim of the activity was to create a game-based learning situation where the students were engaged in a project and were motivated to study. Besides, this project was also developed with the objectives of reinforcing the retention of concepts, developing skills to work in groups and also promoting healthy competition among the students as part of their preparation for their future career.

\section{Method}

The project planned is based on the principle of learning through questions game boards. However, in this case, there is a peculiarity since the students not only are going to reinforce their knowledge when playing the game; they are also the producers of the whole game and therefore they are going to study and practice while the game board is being elaborated.

The activity is developed during the semester when the course takes place and it finishes at the last session. Periodically, at the end of some of the lectures of the course, the students, working in groups, are asked to propose several questions related to the content of the course explained until that moment. 
At this point, the labour of the lecturer is checking the quality of the composition and assuring that the questions proposed and their corresponding answers are correct, giving to the students the proper feedback and indications if part of the elaborated material needs to be modified. Each group only knows its own questions. The remaining work deals with the elaboration of the board.

The agreement on the game rules is a very important part to avoid problems and conflicts in the future. If the game rules are agreed for all the students of the course, then all of them will be obliged to obey such rules.

Finally, to complete the experience, the last session of the course is dedicated to play the developed game. Once the game is over, the students are asked to give their opinions and suggestions about the experience to have the proper feedback. This will help the lecturers to focus their future efforts in the right direction.

\section{Results and Discussion}

The game board elaborated by the students as the final product of the activity is shown in Figure 1. As observed, it is a game board based on the Game of the Goose (a very popular game in Spain) but customized to integrate the game into the context of the subject. Thus, the game consists of 63 numbered spaces arranged in a spiral. The game is played by several teams formed by heterogeneous groups of students. Each team is represented in the board by a piece which is moved by throwing one dice.

Contrary to the traditional game, there are no spaces with gooses or other shortcuts to allow the players to move again. In this case, it is the students' level of knowledge what allow them to continue playing. If a team answers correctly the formulated question, it can move again and try to answer a new question. If the answer given to a question is not correct, the team loses its turn.

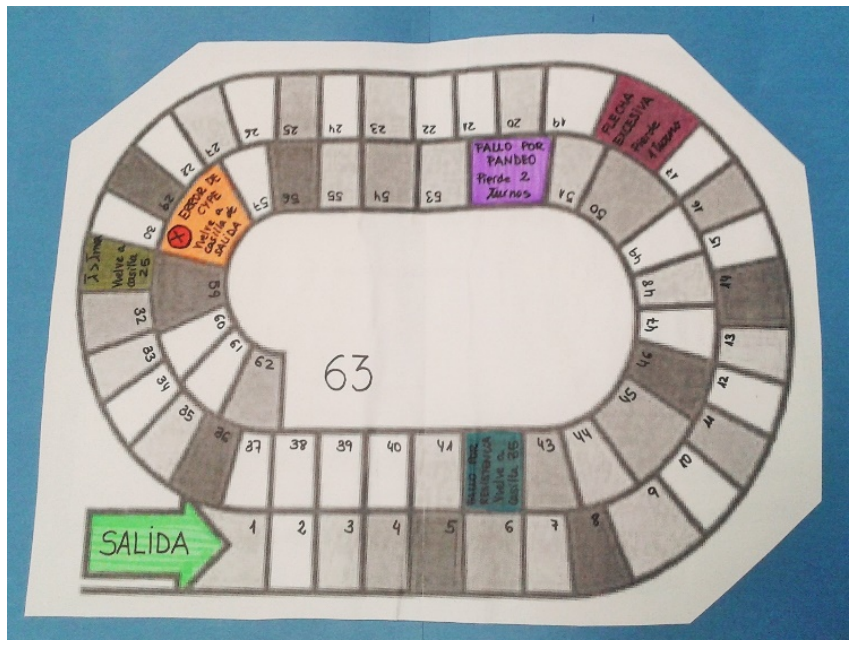

Figure 1. The game board elaborated.

There are some penalty spaces which make the players lose one or more turns if they land on them. Another type of penalty spaces are the ones that oblige the players to move back to a specified space or, in the case of landing in the most harmful, to move back to start.

The penalty spaces are represented by the typical types of failure that can occur in metallic structures. For instance, the space number 52 corresponds to "Buckling 
failure" and landing in it makes the players lose two turns; or the space number 42 is represented by "Cross-sectional resistance failure" and forces the players to move back to the space number 35 .

With regard to the number of students participating in the project, it is necessary to point out the next. The project was carried out during the spring semester of the academic year 2013-2014 and, at the beginning, the percentage of students attending the course was $85 \%$ (30 of the 36 enrolled students attended, in average). It was a really high percentage compared to the number of students attending the last sessions of the course, which was about $48 \%$ (the average number of attendees was 17).

The diminution on the number of students was due to the increase of the work density during the last weeks of the semester jointly with the proximity of the final exams. As a result, the final part of the activity, which dealt with the preparation of the board and the participation in the final competition, was followed by 17 students.

However, there was an increment in the percentage of students who attended the last sessions of the course with respect to the one registered in the academic year 20122013 when the activity was not performed. The percentage of students increased from $30 \%$ to $48 \%$. This shows the commitment of an important part of the students with the activity developed and the fact that it made them maintain their interest in the subject during the whole semester.

Regarding to the groups created during the course to elaborate the questions, they were composed in an informal way and were different each time with no fixed roles established. For the final competition, students formed heterogeneous teams by themselves, without any kind of restriction but the number of components.

In the present work, no quantifiable results about the student satisfaction with the experience were obtained since the activity was not evaluated but, on the contrary, feedback from the students in form of personal opinion and recommendations was collected.

In general, their opinions expressed that they were satisfied with the development of the activity. With regard to working in groups, some of them indicated that although it was an idea that did not motivate them at the beginning, finally they were comfortable with it since the task had been carried out in a relaxed environment. As usual in heterogeneous teams, some of the students were more passive than others but, in general, all of them were participating in the game.

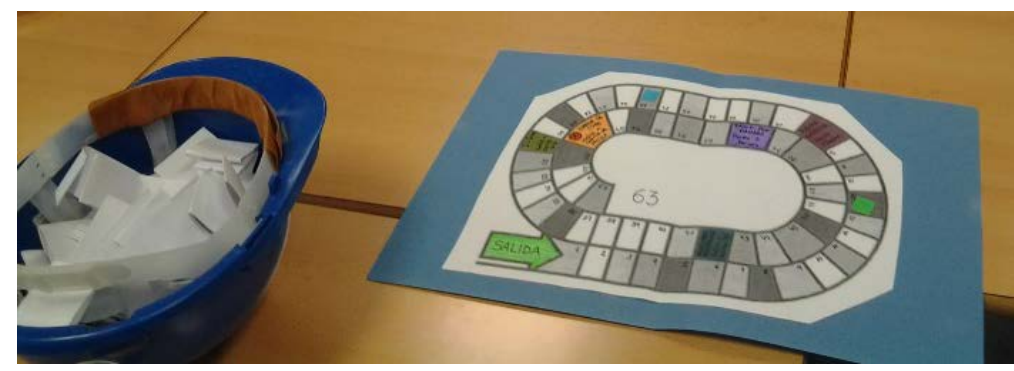

Figure 2. Left, redacted questions in a helmet as a wink to the main topic of the course; right, the game board elaborated. 
Also there were opinions referring to the competition factor. Since the questions they proposed would be included in the game, they were very focused on its elaboration in order to not to facilitate the other groups to win the competition.

Slightly different opinions came from those adult students, generally people with an active professional life, who at the beginning of the project were a little sceptic and did not trust in the effectiveness of the game-based learning. However, these people recognized the novelty of the activity and the effort of the lecturers and students to carry out such task.

With respect to the final stage of the activity, most of them pointed out the importance of seeing that their efforts were worthy because they had built a tool useful to study and review the concepts of the course. Most of the students agreed in being satisfied knowing that they had created something that not only benefited them but also their colleagues.

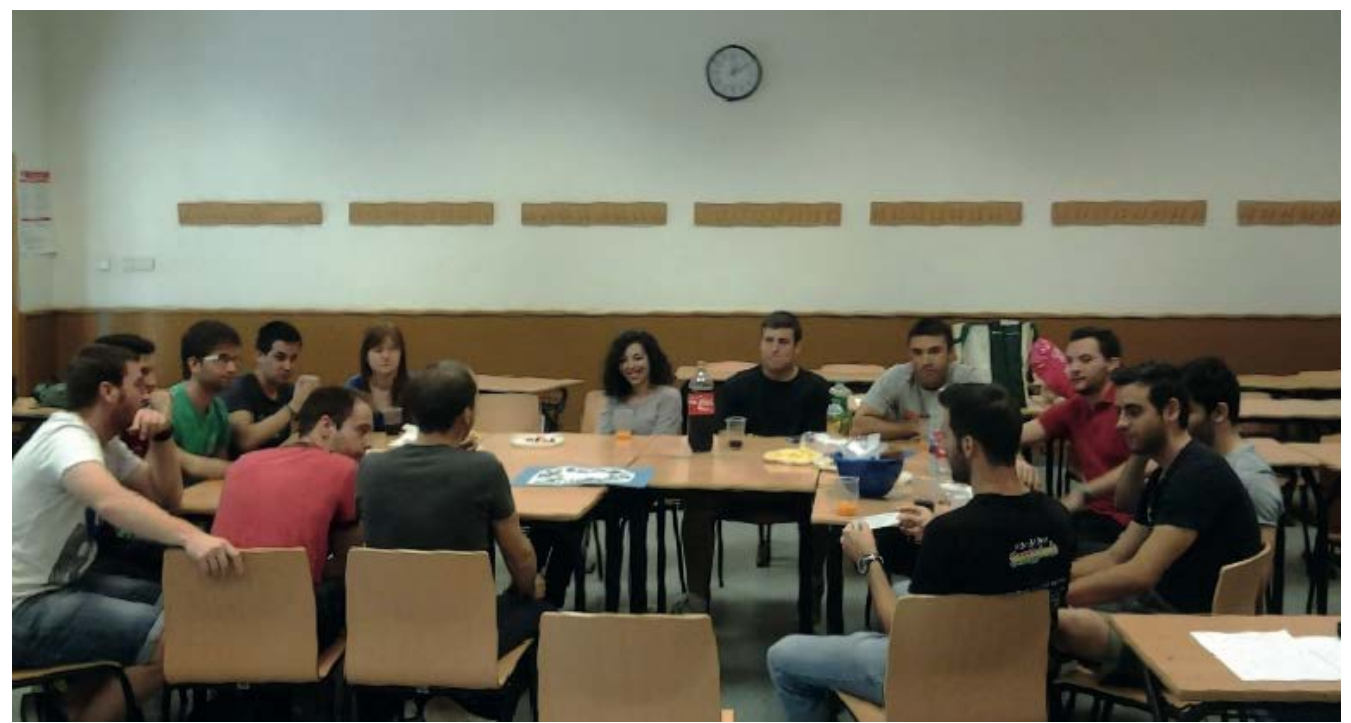

Figure 3. Students during the competition with the questions game board, June 2014.

The authors believe that the familiar atmosphere created helped the students to really enjoy the activity and take profit of it. This enhances the importance of the ludic nature of the activity, which allows the students to not be stressed while they are studying and reinforcing their knowledge.

For future editions of this project, the authors are working in proper questionnaires to accurately capture the satisfaction and opinion of the students about the activity. By means of this, it would be possible to quantify the results. It will allow the lecturers to compare results from different academic years and extract well-founded conclusions.

\section{Conclusions}

After carrying out the presented activity with undergraduate students, the authors of this work have detected that the development of a questions board game can result in a challenging and engaging activity. According to the collected opinions, it was also highly satisfactory since they see their efforts reflected in a very useful tool to review the concepts of the subject. 
Besides, communication and collaboration are enhanced by means of working in groups whereas using the elaborated game as a review tool help to summarize and reinforce essential concepts. In general, students are very interested and motivated to acquire new knowledge during the execution of this project.

Due to the positive results, the authors are determined to repeat this project and apply the gained experience as a starting point for a better structured experiment. Controls in form of pre and post questionnaires could be used as a better manner to collect the opinions and satisfaction level of the students and to detect changes in their motivation and knowledge as a result of participating in the activity.

\section{References}

Baker, A., Navarro, E. O., and van der Hoek, A. (2003). Problems and programmers: an educational software engineering card game. Proceedings of the 25th International Conference on Software Engineering, 614-619. Hilton, Portland.

Carlson, S. (2005). The Net Generation goes to college. The Chronicle of Higher Education, 52(7), A34.

Fisch, M.S. (2005). Making Educational Computer Games 'Educational'. Proceedings of the 2005 conference on Interaction design and children, Boulder, Colorado, ACM Press, New York, NY, 55-61.

Hays, R.T. (2005). The effectiveness of instructional games: A literature review and discussion. Technical Report No. NAWCTSD-TR-2005-004, Naval Air Warfare Center Training Systems Division, Orlando, FL, 2005.

Katmada, A., Mavridis, A., and Tsiatsos, T. (2014). Implementing a Game for Supporting Learning in Mathematics. The Electronic Journal of e-Learning, 12(3), 230-242.

Marzano, R. J. (2007). The art and science of teaching: A comprehensive framework for effective instruction. Alexandria, VA: Association for Supervision and Curriculum Development.

Moseley, A. (2011). Pass go Quickly: Use of a Board Game to Provide Efficient and Effective Training in Course Design Concepts. Proceedings of the 5th European Conference on Game-Based Learning. Athens: University of Athens.

Salies, T. G. (2002). Simulations/gaming in the EAP writing class: Benefits and drawbacks. Simulation \& Gaming, 33(3), 316-329.

Sharp, L. A. (2012). Stealth learning: Unexpected Learning Opportunities Through Games. Journal of Instructional Research, 1, 42-48.

Whitton, N., (2012). The place of game-based learning in an age of austerity. Electronic Journal of e-Learning, 10(2), 249-256. 